\title{
La influencia del imaginario de la pornografía hegemónica en la construcción del deseo sexual masculino prostituyente: un análisis de la demanda de prostitución
}

\author{
The Influence of Hegemonic Pornography's Imagery on \\ the Construction of Buyers' Masculine Sexual Desire: An \\ Analysis of the Demand for Prostitution
}

\begin{abstract}
RESUMEN
En la actualidad, uno de los grandes retos del feminismo es enfrentarse a las diversas formas de mercantilización de los cuerpos de las mujeres que estamos contemplando en nuestra sociedad. Una de estas formas la encontramos en la prostitución y la trata: fenómenos en que los varones pagan, entre otras cosas, por acceder sexualmente a los cuerpos de las mujeres. En este artículo pretendemos analizar una de las causas últimas de esta forma de mercantilización: la construcción del deseo sexual masculino prostituyente. Para ello estudiaremos cómo se construye la masculinidad hegemónica y qué función cumple en ella la sexualidad; posteriormente, analizaremos en qué medida la pornografía hegemónica contribuye a cosificar a las mujeres, colaborando en la construcción de un deseo sexual masculino que puede llevar a los varones al consumo de prostitución.

Palabras clave: masculinidad hegemónica, deseo sexual masculino prostituyente, pornografía hegemónica, prostitución.
\end{abstract}

\begin{abstract}
Currently, one of the great challenges for feminism is confronting the different ways in which women's bodies are commercialized in our society. One of these ways is prostitution and sexual slavery: phenomena where men pay to have sexual access to women's bodies, among other things. This article pretends to analyse one of the causes of this form of commercialization: the construction of a buyer's masculine sexual desire. To this end, we are going to study how hegemonic masculinity is constructed and the function of sexuality in it. After, we will analyse to what extent hegemonic pornography contributes to the objectification of women, collaborating in the construction of a masculine sexual desire that can lead men to consume prostitution.
\end{abstract}

Keywords: Hegemonic masculinity, buyers' masculine sexual desire, hegemonic pornography, prostitution.

\section{Sumario}

1.- Prostitución y trata de mujeres con fines de explotación sexual. 2.- Masculinidad hegemónica. 3.- Pornografía hegemónica. 4.- Conclusiones. ¿Por qué tantos varones consumen prostitución? - Referencias bibliográficas. - Recursos electrónicos.

1 Universidad Rey Juan Carlos, Contratada FPU del MECD, monica.alariogavilan@gmail.com

ASPARKÍA, 33; 2018, 61-79 - ISSN: 1132-8231 - DOI: HTTP:/ / DX.DOI.ORG/10.6035/AsPARKIA.2018.33.4 


\section{Prostitución y trata de mujeres con fines de explotación sexual}

Si bien, hasta hace unos años, los análisis de la prostitución tendían a centrarse en las mujeres en situación de prostitución, en este artículo seguimos la línea propuesta por De Miguel (2012): pretendemos centrarnos en los varones demandantes. La recopilación Elementos para una teoría crítica del sistema prostitucional (Nuño y De Miguel, 2017) es una de las más actuales en esta línea. Según afirma el Protocolo de Palermo, ratificado por España, «la oferta de los servicios sexuales existe y el tráfico de mujeres con fines de explotación sexual no cesa de desarrollarse, porque existe a su vez una creciente demanda por parte de los clientes. Es la ley del mercado: existe oferta porque hay demanda» (Comisión para la Investigación de Malos Tratos a Mujeres, 2006). En este artículo partimos de la constatación, revelada en diversos estudios, de que «el cliente es central en el estudio de la prostitución pues sin él no existe esta actividad» (Meneses, 2010: 394).

Los últimos datos sobre consumo de prostitución muestran que el $90 \%$ de personas en situación de prostitución son mujeres, mientras que el 99,7\% de personas que demandan prostitución son hombres (Ayuntamiento de Sevilla, 2011), por lo que podemos hablar de un fenómeno claramente relacionado con la construcción del género. Según estos datos, la demanda de ese $10 \%$ de personas en situación de prostitución que no son mujeres, es también principalmente masculina. Además, España es el primer país consumidor de prostitución de Europa (APRAMP, 2011) y el primer destino de víctimas de trata (Meneses, 2016).

Según Naciones Unidas (2010), un 39\% de los varones del Estado Español ha consumido prostitución: casi 4 de cada 10 varones. Por ello, no podemos analizar el consumo masculino de prostitución como si fueran casos puntuales, sino como un fenómeno que responde a causas sociales o estructurales.

¿Qué es lo que encontramos en el consumo de prostitución? Varones que pagan una cantidad variable de dinero por acceder sexualmente al cuerpo de una mujer, independientemente de lo que ella sienta o desee. Ese «acceder sexualmente», además de la función de satisfacer un deseo sexual, tiene otras funciones de las que hablaremos más adelante.

La pregunta que pretendemos iluminar en este artículo es la siguiente: ¿cómo es posible que tantos varones ${ }^{2}$, en el marco de una sociedad legalmente igualitaria, deseen, como afirma Amelia Tiganus ${ }^{3}$, pagar por penetrar a mujeres que no les desean (Escalada, 2016)? ¿Cómo es posible que tantos varones puedan disfrutar de acceder a cuerpos de mujeres para tener una experiencia sexual sin reciprocidad, en una situación de desigualdad tan clara?

Si bien el 99,7\% de personas que consumen prostitución son varones, no todos los varones, pese a haber sido socializados en el género masculino, consumen pros-

2 Tantos como para que, como afirma Sambade (2017: 169), «la prostitución y la trata de mujeres sean junto con el tráfico de armas y de drogas los negocios criminales que ponen en circulación más dinero en el planeta».

3 Amelia Tiganus, superviviente y activista en Feminicidio.net, estuvo (como afirmó en Salvados: Las Invisibles) «atrapada durante cinco años en el sistema prostitucional». 
titución. Para aproximarnos a las causas de que tantos varones hayan consumido o consuman prostitución, lo primero que debemos preguntarnos es: ¿qué tienen en común esos casi 4 de cada 10 varones? ¿Qué les ha llevado a consumir prostitución?

Diversas investigaciones realizadas en España (Gómez, Pérez y Verdugo, 2015; Barahona y García, 2003; Comisión para la Investigación de Malos Tratos a Mujeres, 2006; López y Baringo, 2006; Askabide, 2008; Meneses y Rua, 2011; Ranea, 2017; Gómez, 2017), muestran que los consumidores de prostitución son un grupo con características sociodemográficas heterogéneas. No existe un perfil sociológico concreto: ni la edad, ni la clase social, ni la etnia, ni el nivel de formación, ni el hábitat, ni la ideología política ni la ocupación sirven para crear un perfil estadístico. Lo único que tienen en común todos ellos es haber sido socializados en el género masculino. Más concretamente, «el consumo de sexo de pago por parte de los varones se deriva de una forma concreta de entender el "ser hombre" (Gómez, Pérez y Verdugo, 2015: 26), de un tipo concreto de masculinidad. A esta masculinidad nos referiremos como «masculinidad hegemónica»: de ella hablaremos detenidamente a continuación. La pregunta, por tanto, es: ¿cómo es esa socialización masculina que hace que los varones consuman prostitución? ¿Cómo se construye el deseo sexual masculino prostituyente?

\section{Masculinidad hegemónica}

Los géneros, como sabemos, son construcciones sociales. Por tanto, son distintos según en qué sociedad los analicemos y también cambian en función del tiempo. Ahora bien: si los géneros no son naturales, si no nacemos con ellos incorporados a nuestra manera de vivir, ¿cuándo y cómo los aprendemos?

La socialización de género es el proceso por el que cada persona interioriza los modelos de masculinidad y feminidad de su cultura e incorpora a su manera de vivir y a su personalidad el género que le corresponde. Es, por tanto, el proceso por el cual una niña aprende en qué consiste ser una niña, y un niño aprende en qué consiste ser un niño. Ya en 1987, en el libro Elementos para una educación no sexista: guía didáctica de la coeducación del Feminario de Alicante, o en 1988, en Rosa y azul. La transmisión de los géneros en la escuela mixta de Subirats y Brullet, se estudiaba en profundidad la transmisión de los géneros en la escuela mixta, uno de los agentes de socialización principales, aunque no el único. Posteriormente, expertas en el tema como Simón (2010), Herranz (2006), Subirats $(1999,2013)$ o esta última autora junto con Tomé (1992), han seguido analizando la socialización de género.

En este artículo pretendemos analizar la masculinidad hegemónica, una manera concreta de entender qué significa «ser hombre» y de vivir la masculinidad. Connell (1995) conceptualizó la masculinidad hegemónica como la práctica de género que garantiza la posición dominante de los hombres y la subordinación de las mujeres. Según Beasley (2008), la masculinidad hegemónica es un mecanismo político que genera un modelo normativo de lo que es ser un hombre «de verdad», precisamente el que reproduce el patriarcado y la desigualdad de poder entre hombres y mujeres. Así, sería «una encarnación del poder en sí misma, que se representa en 
determinados comportamientos, actitudes, formas de relacionarse que contribuyen a sostener los privilegios masculinos» (Ranea, 2016: 3).

Es importante entender cómo se construye esta masculinidad para comprender, posteriormente, cómo se construye la sexualidad y el deseo sexual masculino a los que va unida. En este apartado y en los sucesivos iremos enumerando algunos aspectos de dichas construcciones; aspectos relevantes para el análisis de por qué tantos varones consumen prostitución.

En primer lugar, las mencionadas expertas en socialización de género coinciden en que esta masculinidad, transmitida a los niños en dicho proceso, está construida en oposición a lo socialmente considerado femenino, situándolo como inferior. Esto se entiende mejor si lo situamos en nuestro contexto: vivimos en un patriarcado, sistema de dominación de los hombres sobre las mujeres en que, como sabemos, existe una jerarquía entre los géneros, ocupando el masculino el lugar superior y el femenino, el inferior. El niño deberá interiorizar y mostrar esa masculinidad que se opone a la feminidad y la devalúa, posicionándose en el lugar superior. Conseguirlo conlleva diversos privilegios.

Así, podemos observar cómo se genera, ya desde la infancia en las escuelas, un grupo de varones, a los que Simón (2010: 69) denomina el «club de los igualessuperiores», haciendo referencia a que muestran ser iguales entre ellos, pero superiores al resto. En él tienen cabida los niños que muestren una masculinidad hegemónica, pero no los más femeninos ni, por supuesto, las niñas.

Un varón solo formará parte del grupo dominante si los demás miembros del mismo le reconocen como tal. Por ello, en segundo lugar, ser reconocido como parte de ese grupo por los demás miembros es de enorme importancia para los varones. Ahora bien: la masculinidad hegemónica no es algo que se «posea» de manera estable, sino algo que se demuestra. Por ello, en tercer lugar, los varones que responden a esta masculinidad hegemónica van a sentir la necesidad de demostrar constantemente a los demás (y a sí mismos) que son «suficientemente hombres» como para pertenecer al grupo dominante. Recordemos que esto equivale a demostrar que son capaces de situarse por encima de las mujeres. Esta necesidad les acompañará desde la infancia y durante toda la vida.

Si muestran no ser "suficientemente hombres», quedarán relegados a la posición de las niñas y los niños femeninos, lo que conlleva un castigo social y supone la pérdida de los privilegios que otorga pertenecer a un grupo dominante. Comentarios en tono despectivo como «no llores, que pareces una niña» o insultos como «nenaza»o «mariquita», les están transmitiendo que parecer niñas y no adaptarse a la masculinidad hegemónica supone para ellos una humillación. En los centros educativos se puede observar qué ocurre con los niños que no se adaptan a este modelo: suelen ser excluidos del grupo y, muy habitualmente, sufren bullying.

Cuando los miembros del grupo dominante refuerzan su masculinidad en grupo y se reconocen como iguales entre ellos y como capaces de dominar al resto, generan un tipo de vínculo concreto al que denominamos «fratría» (Amorós, 2005). La fratría es la complicidad de los varones con respecto a la dominación de las mujeres. Es relevante que entendamos que la necesidad de mostrar esa superioridad 
constantemente se debe a que dicha superioridad no es natural (y, por tanto, no es inevitable) sino construida. Si fuera natural e inevitable, los varones no tendrían que intentar demostrarla constantemente: se impondría por sí sola. Pero, siendo una construcción social, puede cambiar o desaparecer, lo que haría a los varones perder su situación de privilegios.

El feminismo lleva muchos años luchando para que esta construcción que afirma la superioridad de los varones sobre las mujeres desaparezca. Gracias a esta lucha, la sociedad ha ido cambiando. Hace (no demasiados) años, las leyes daban a los varones derechos de los que las mujeres no disponían, o hacían a estas depender de aquellos, reforzando directamente su sensación de superioridad. En la actualidad, vivimos en una sociedad en que la igualdad a nivel legal está conseguida. Pero si bien la sociedad ha ido evolucionando, la masculinidad hegemónica, en lo relativo a su necesidad de confirmación de la capacidad de dominar a las mujeres, no lo ha hecho. Adaptarse a la sociedad por la que lucha el feminismo, para esta masculinidad hegemónica, implicaría desaparecer; desaparición que eliminaría los privilegios de los varones.

Este tipo de masculinidad se aprende, y como todo lo aprendido, se puede desaprender. Hay varones que a lo largo de su vida llegan a desarrollar una conciencia crítica con respecto a este modelo de masculinidad en que se les ha socializado y la desaprenden en una $u$ otra medida. Esto es complejo, porque toda nuestra cultura muestra este modelo de masculinidad como un éxito y adaptarse a él conlleva privilegios de todo tipo. Así, hay muchos varones que nunca llegan a desarrollar esa conciencia crítica. Es de estos de los que se va a hablar en el presente artículo.

Los varones que responden a esta masculinidad hegemónica y se resisten a la pérdida de sus privilegios siguen tratando de demostrar esa supuesta superioridad. Si bien los terrenos en que pueden hacerlo se están reduciendo, es cierto que todavía quedan algunos. Uno de ellos, que vamos a analizar con más profundidad a continuación, es la sexualidad; y el lugar donde se sienten legitimados para dar rienda suelta a esa sexualidad que pretende dominar a las mujeres es el prostíbulo.

\subsection{Relevancia de la sexualidad en la masculinidad hegemónica}

Según afirman diversos autores, la masculinidad hegemónica, históricamente, ha ido unida a tres exigencias morales que han actuado en la subjetividad masculina como legitimación de los privilegios patriarcales: la exigencia de provisión, de protección y de potencia sexual (Gilmore, 1994). Cumpliendo ellos con estas exigencias, mostraban y confirmaban directamente su superioridad (en tanto que eran necesarios para la supervivencia de las mujeres y de las familias), y, como contrapartida a cumplirlas, obtenían ciertos privilegios.

Actualmente las figuras del varón proveedor y del varón protector son cada vez menos necesarias. Así, en estos dos terrenos (la provisión y la protección), los varones cada vez encuentran más dificultad para afirmar su superioridad. Ahora bien: esto no ha ocurrido en la misma medida en el terreno de la sexualidad y en lo relativo a la potencia sexual. 
Así, en cuarto lugar, como muestran Favaro y De Miguel (2016), la sexualidad permanece como uno de los terrenos en que los varones todavía tienen la posibilidad de reafirmar su masculinidad. Y, en tanto que en otros terrenos cada vez es más complejo, hacerlo en la sexualidad se convierte en una exigencia. Como en la sexualidad deben mostrar que son «suficientemente hombres», su vivencia de la misma va a ir unida a la confirmación de esta masculinidad hegemónica, a la capacidad de dominar a las mujeres (Marqués y Osborne, 1991).

En quinto lugar, si esa confirmación de la masculinidad adquiere su máximo sentido en tanto que es reconocida por los otros miembros del grupo dominante, y esto cada vez ocurre en menos ámbitos, en la sexualidad, el varón debe demostrar, ante sí mismo y ante el grupo de iguales, que es un «hombre de verdad». «Si en el pasado los valores tradicionales del varón eran la paternidad responsable y el rol de protector y proveedor de la familia, hoy en día la virilidad se construye a través de una "compulsiva vida sexual" de la que se presume delante del grupo de pares masculinos» (Gómez, Pérez y Verdugo, 2015: 26).

Este «presumir» es muy relevante. Para conseguir el reconocimiento del grupo de iguales va a ser habitual que los varones compartan sus «hazañas» sexuales; que compartan pornografía o que la vean en grupo; que, como afirma Salazar (2017: 165), acudan en grupo a los burdeles, incorporen la posibilidad de consumir prostitución en su ocio o incorporen a mujeres en situación de prostitución en sus celebraciones o negocios; y, como estamos comprobando en diversos casos en la actualidad, que ejerzan violencia sexual en grupo, en manada. Con ello se desarrolla un sentimiento muy fuerte de fratría, basado en estos casos en la complicidad de los varones con respecto a la dominación sexual de las mujeres.

\subsection{Construcción del deseo sexual masculino}

Las características de la masculinidad hegemónica explicadas hasta ahora se introducen también en la sexualidad masculina hegemónica y toman sentido en ella. A continuación, analizaremos otras características de la sexualidad masculina hegemónica relevantes para nuestro análisis, siguiendo con la numeración anterior.

Las socializaciones de género se apoyan, según Simón (2010: 92) en tres pilares. Uno de ellos, al que queremos hacer referencia, es la educación sentimental sexista. Por medio de ella, se enseña a niños y a niñas qué emociones deben o no deben tener y cómo deben o no deben expresarlas. Así, siendo los géneros complementarios, la socialización masculina va a potenciar a los niños las emociones y las expresiones de las mismas que la socialización femenina castigue a las niñas, y viceversa. Afirmó De Beauvoir en El segundo sexo (1949), mientras el género femenino consiste en un «ser para otros» (poner al otro por delante de una misma, estar siempre pendiente del cuidado del otro) que puede acabar haciendo que las mujeres confundan el bienestar propio con el ajeno; el género masculino consiste en un «ser para sí mismo», en un sentirse el centro, que puede llevar a los varones a no tener en cuenta el bienestar o el malestar ajeno. Coherentemente con esto, en esta educación sentimental sexista, los niños van a aprender a negar o a 
reprimir emociones relacionadas con la vulnerabilidad, la tristeza, la ternura o la empatía.

En sexto lugar, si bien el placer de las mujeres, debido a la socialización femenina (que potencia la empatía y el cuidado ajeno), suele estar atravesado por la reciprocidad y por la percepción del placer de la otra persona, el deseo sexual masculino hegemónico va a estar atravesado no solo por el protagonismo del deseo propio, sino por la falta de empatía con las emociones de la mujer con quien mantengan relaciones sexuales. Esto es relevante en el análisis del consumo de prostitución.

Como sabemos, en la masculinidad hegemónica, la sexualidad tiene un papel central. La subjetividad masculina hegemónica exige la encarnación de una sexualidad con características muy concretas: el varón debe estar siempre dispuesto a mantener relaciones sexuales y cuantas más consiga mantener mayor será su hombría; estas relaciones deben ser estrictamente heterosexuales, falocéntricas y coitocéntricas, y él debe ser la parte activa y dominante y mostrar su alto rendimiento y su potencia.

El deseo sexual masculino se ha conceptualizado a lo largo de la historia, como explica de manera brillante Puleo en su obra Dialéctica de la sexualidad (1992), como una fuerza de la naturaleza, un torrente imparable. Ha sido conceptualizado no como deseo, sino como necesidad; y, en tanto que necesidad, como algo que tiene que poder ser satisfecho. Así, en séptimo lugar, hemos heredado una concepción de la sexualidad masculina construida a lo largo de toda la historia que afirma que la satisfacción de los deseos sexuales masculinos es un derecho porque estos no son deseos sino necesidades. En esta concepción, que ha justificado la violencia sexual y el consumo de prostitución a lo largo de la historia, se sigue apoyando la sexualidad masculina hegemónica.

Ahora bien: la satisfacción del deseo sexual es algo que, por medio de la masturbación, cada varón puede obtener en solitario. Por el uso que se ha dado a este argumento podemos concluir que lo que se está defendiendo no es únicamente el derecho de los varones a satisfacer sus deseos sexuales, sino su derecho a satisfacerlos utilizando el cuerpo de una mujer; o, en otras palabras, el derecho de los varones a ser servidos sexualmente por las mujeres. Esto legitima de manera directa el consumo de prostitución.

El proceso de socialización de los hombres está construido sobre la certeza de que su sexo les otorga derecho a disponer de su entorno, del espacio y del tiempo de otros y, en primer lugar, otras. Este derecho se extiende también al cuerpo y a la sexualidad de las mujeres. De allí hay sólo un paso a que, tratándose de un derecho, es legítimo conseguirlo y preservarlo, aunque sea con violencia (Szil, 2006).

\section{Pornografía hegemónica}

El deseo sexual masculino que estamos analizando se construye, entre otras cosas, a través de la pornografía hegemónica. A continuación, analizaremos algunos mensajes de esta pornografía que colaboran con la creación del deseo sexual masculino que hace que los varones consuman prostitución. 
Los vínculos entre pornografía y prostitución son muy diversos. Por un lado, ambas forman parte de la industria del sexo: como muestra López (2017), tras ellas están los mismos lobbys. Por otro, «la pornografía es el marketing de la prostitución» (Szil, 2006: 2). Finalmente, en lo que vamos a centrarnos a continuación, el deseo sexual masculino que construye la pornografía hegemónica encuentra en la prostitución el terreno ideal para satisfacerse. Y es que, como afirma Walker (2010), el sexo de la pornografía es el sexo de la prostitución: sin elección, sin reciprocidad y sin emotividad.

\subsection{Puntos de partida de la pornografía hegemónica}

En este apartado describiremos parte de lo que podemos encontrar en dos páginas web de pornografía hegemónica: Pornhub y Xvideos. Estas son, según los rankings de Alexa y Webempresa, dos de las páginas web (no de pornografía, sino de cualquier contenido) más visitadas en nuestro país. En ambos rankings están entre los puestos 16 y 27.

La organización de Pornhub es bastante intuitiva. Los vídeos están clasificados en categorías. También hay un buscador donde se pueden buscar vídeos por palabras. Ofrece una página para varones homosexuales y otra para varones heterosexuales. Los sujetos a los que va dirigida la pornografía hegemónica son los varones; precisamente quienes consumen prostitución. En este artículo vamos a centrarnos en la pornografía hegemónica dirigida a varones heterosexuales debido a que estamos analizando la masculinidad hegemónica.

\subsubsection{La cosificación y la sexualización de las mujeres}

La cosificación es el proceso por el cual se despoja a una persona de lo que le hace ser una persona, reduciéndole a la condición de cosa. En el caso de las mujeres, se las reduce a cuerpos.

Este proceso es relevante en el tema que estamos tratando porque es un paso necesario para la mercantilización de los cuerpos de las mujeres y previo a la misma. Actualmente vivimos en una sociedad en que el discurso mayoritario y socialmente aceptado afirma que no se puede vender ni comprar a una persona. ¿Cómo es esto compatible con que diversas formas de mercantilización de los cuerpos de las mujeres se estén asumiendo desde tantos sectores sociales de manera acrítica ${ }^{4}$ ? $\mathrm{Si}$ bien esta no es una pregunta sencilla, podemos aventurarnos a dar dos respuestas. La primera: porque vivimos en un patriarcado que cosifica a las mujeres convirtiéndolas en cuerpos; y partiendo de esta cosificación, considerar que es legítimo vender o alquilar ciertos trozos de esos cuerpos no es contradictorio con considerar que una persona no puede venderse ni comprarse. La cosificación hace que ya no se esté mercantilizando una persona, sino un trozo de cuerpo, un objeto. La segunda: porque esta mercantilización está apoyada por el discurso neoliberal e individualista que afirma la legitimidad de cualquier intercambio siempre que haya consentimiento; eso sí, ese discurso habla de un consentimiento descontex- 
tualizado, sin tener en cuenta el contexto social ni las diversas desigualdades que lo atraviesan (De Miguel, 2015).

De la mano de esta cosificación, llega también la sexualización, proceso por el cual se connota eróticamente algo que no tendría por qué tener esta connotación. Esto ocurre con los cuerpos de las mujeres. Así, tras reducirlas a cuerpos, se les añade la categoría «sexuales». Estos dos procesos convierten a las mujeres en objetos sexuales, en cuerpos para el placer sexual del varón (que se mantiene en posición de sujeto).

Ahora bien: ¿cómo es y dónde se da este doble proceso de cosificación y sexualización de las mujeres? Este proceso es un continuo. Podemos observar niveles más sutiles de cosificación y sexualización en la publicidad, en el arte, en la música, en el cine... Si avanzamos un poco más en ese continuo, encontramos una cosificación y sexualización bastante fuertes en la pornografía hegemónica; finalmente, el punto más extremo del proceso lo encontramos en la violencia sexual y el consumo de prostitución (Salazar, 2017: 165).

¿Cómo se transmiten en la pornografía la cosificación y la sexualización de las mujeres? Si analizamos las categorías de la página Pornhub para varones heterosexuales, vemos que hacen referencia o bien a qué tipo de prácticas podemos ver en los vídeos o bien a cómo son los cuerpos de las mujeres que aparecen. De las categorías del primer tipo hablaremos más adelante. Entre las categorías del segundo tipo encontramos Adolescente, Jovencitas/Viejos (vídeos en que aparecen chicas adolescentes con hombres adultos o ancianos), Maduras, Madre a la que me follaría (del inglés MILF, acrónimo de Mom I'd Like to Fuck), Alemanas, Asiáticas, Brasileñas, Coreanas, Francesas, Indias, Japonesas, Negras, Rusas, Castañas, Pelirrojas, Rubias, Gordas, Tetas pequeñas, Tetonas, Lesbianas, Niñeras, Zorras, Famosas... Como vemos, un amplio catálogo en que la conversión de las mujeres en cuerpos y la sexualización de trozos o características de los mismos se hacen absolutamente presentes.

La pornografía hegemónica, que colabora en la construcción del deseo sexual masculino hegemónico, enseña a los varones a convertir a las mujeres en objetos sexuales. La cosificación y la sexualización son relevantes en el consumo de prostitución porque para que un varón pueda consumir prostitución tiene que poder no empatizar con las emociones reales de la mujer que tiene en frente. Estas emociones pueden ir desde la indiferencia al miedo, dolor, asco o rechazo. El varón tiene que poder excitarse a pesar de ellas (o incluso precisamente con ellas, como veremos más adelante): tiene que poder considerar que esa mujer es sólo un cuerpo disponible para uso sexual. Así, si la socialización de los varones ya castigaba la empatía, la pornografía les enseña a convertir a las mujeres en objetos sexuales disponibles para su satisfacción, eliminando de manera absoluta cualquier reconocimiento de las mismas como personas con emociones, deseos y autonomía.

\subsubsection{La centralidad del deseo sexual masculino}

En la pornografía, el único deseo relevante es el del varón. Él es quien tiene un deseo que va a verse satisfecho empleando para ello el cuerpo de una mujer. Da igual cuál sea ese deseo: puede desear producirle a la mujer placer, producirle 
dolor, ser dominado por ella, someterla, humillarla... Desee lo que desee, en la pornografía lo va a obtener. Y lo va a obtener independientemente de lo que sienta la mujer: da igual que sienta placer, dolor, miedo, angustia, indiferencia, desagrado...

En la pornografía el placer de las mujeres es irrelevante. Encontramos que incluso en los vídeos en que ellas parecen alcanzar el orgasmo no suele haber estimulación clitoriana. Además, según muestra Favaro (2015), el modelo propuesto por la pornografía está colaborando en la creación de una sexualidad femenina pornificada, dedicada a satisfacer los deseos del varón.

Así, en la pornografía hegemónica, como afirma Cobo (2017), el reparto de papeles es claro: él es el sujeto y ella el objeto, y él tiene un deseo (no exento de violencia) que va a satisfacer usando el cuerpo de ella. Aquí, las mujeres no son personas con las que vincularse desde el respeto y la reciprocidad: son medios para el fin de que los varones afirmen su masculinidad y obtengan placer sexual. Esto refuerza el mencionado discurso que afirma que los varones tienen derecho a satisfacer sus deseos sexuales empleando para ello el cuerpo de una mujer; discurso que, de manera muy clara, legitima el consumo de prostitución.

\subsubsection{Unión de las dos funciones de la sexualidad en la masculinidad hegemónica}

Además, la pornografía hegemónica enseña a los varones a unir las dos funciones que cumple la sexualidad en la masculinidad hegemónica. En esta pornografía van a encontrar un modelo de sexualidad en que se aúnan la satisfacción de sus deseos sexuales y su afirmación como capaces de dominar a las mujeres.

¿Cómo se realiza esta unión? Según es presentado en la pornografía, «el deseo masculino ha erotizado la devaluación de lo femenino. Esta devaluación es necesaria psicológicamente no sólo para cumplir con el deseo, sino también para construir su subjetividad, su identidad, su masculinidad, y se retroalimenta en ella» (Gimeno, 2012: 234). Las funciones de satisfacer sus deseos sexuales y de confirmar la masculinidad se unen en la erotización de la devaluación de lo femenino. Así, «las mujeres son objetualizadas y deshumanizadas [...] en aras tanto de la satisfacción sexual de los varones, como de la confirmación de su masculinidad» (Sambade, 2017: 171). El deseo sexual masculino prostituyente parte de una connotación erótica del poder de los varones sobre las mujeres y de la devaluación de éstas.

\subsection{Mensajes de la pornografía hegemónica}

¿Qué transmite la pornografía hegemónica a los varones y cómo colaboran con la construcción del deseo sexual masculino prostituyente?

\subsubsection{Erotización del dolor físico de las mujeres}

Algo que observamos constantemente en la pornografía es la presentación del dolor físico de las mujeres como algo erótico. Para ilustrarlo, ofrecemos algunos ejemplos de prácticas que podemos encontrar en la pornografía hegemónica. 
Entre las categorías que hacen referencia a las prácticas que podemos ver en los vídeos encontramos Doble penetración (práctica en que dos hombres penetran a una mujer, ya sea ambos vaginalmente, ambos analmente, o uno vaginal y otro analmente) y Fisting (práctica consistente en la introducción del puño o parte del brazo por la vagina o el ano, en esta página, de una mujer). Otra práctica muy habitual (también en la pornografía amateur) es el face fucking (follarse la cara de alguien), throat fucking (follarse la garganta de alguien) o gagging (del inglés gag, tener arcadas). Esta práctica es parecida a una felación solamente que en lugar de ser la mujer quien mueve la cabeza, es él quien agarra su cabeza y hace los movimientos con la pelvis, controlando el ritmo, la profundidad y la fuerza. En esta práctica ellos hacen movimientos cada vez más rápidos y profundos y ellas se atragantan, tosen, tienen arcadas y podemos llegar a ver (aunque es menos habitual) cómo vomitan. Azotar a las mujeres en la cara, los pechos, los muslos, el culo o la vulva, escupirlas, tirarles del pelo, agarrarles del cuello... son complementos absolutamente normalizados que pueden acompañar a cualquier otra práctica.

Estos vídeos tienen una consecuencia importante: enseñan a los varones a connotar eróticamente el producirles dolor físico a las mujeres durante las relaciones sexuales. La connotación sexual del dolor físico de las mujeres es relevante para nuestro estudio por dos motivos: por un lado, porque los varones que no quieran producírselo a sus parejas y tengan este deseo, podrán satisfacerlo con las mujeres en situación de prostitución, con quienes no tienen que empatizar; por otro lado, porque cuando encuentren situaciones en que estén produciendo dolor físico a una mujer en las relaciones sexuales, en lugar de sentir rechazo, podrán excitarse con ello.

\subsubsection{Erotización de la falta de deseo de las mujeres}

Este es un mensaje altamente relevante tanto en la construcción del deseo sexual masculino prostituyente como en la reproducción de la violencia sexual. Hace que los varones puedan excitarse con la falta de deseo de las mujeres, algo que van a encontrar en la prostitución.

En la pornografía, una gran parte de los vídeos presentan situaciones en que durante la primera parte de la escena sexual no hay deseo ni consentimiento por parte de las mujeres, pero más adelante ellas muestran que esas relaciones sexuales les producen placer.

En el vídeo Taxi falso estudiante inocente hace sexo anal en el asiento de atrás, vemos a una chica, estudiante de intercambio, que coge un taxi para ir a la universidad. Al llegar, ella le dice que no tiene dinero. Él le propone que le haga una felación y ella se niega. Él responde que la va a dejar tirada «en mitad de la nada», por lo que ella accede. Después, él dice que quiere «follársela», y ella responde que no. Entonces él le explica que lo ha grabado todo y que si no accede subirá el vídeo a Internet. Finalmente practican un coito vaginal y anal en que ella parece disfrutar. Este vídeo tenía 5.691.901 visitas el 14/02/2018. Se capta que ella realiza las prácticas bajo presión, coacción y chantaje, y que en toda la primera parte no hay ni deseo ni consentimiento; pero al final parece disfrutar. 
Otros títulos de vídeos en que vemos situaciones similares son Adolescente se despierta con el pene de su hermanastro en la boca, se lo folla mientras sus padres duermen (25.368.664 visitas a día 12/02/2018), Hermanastro se aprovecha de su hermana pequeña (39.198.523 visitas a día 12/02/2018) y Padrastro se coge a la hija y a sus amigas (41.454.277 visitas a día 12/02/2018).

¿Qué mensajes transmiten estos vídeos? El primero: que mantener relaciones sexuales con una mujer que no lo desea es excitante. El segundo: que, en el fondo, todas lo están deseando, aunque no lo parezca. Así, si bien es cierto que se presentan situaciones en que se está dando violencia sexual, esto aparece encubierto para el consumidor, porque se le repite incansablemente que a ellas finalmente les encanta. Esto colabora en la construcción del deseo sexual masculino prostituyente porque hará que al varón le parezca excitante mantener relaciones sexuales con una mujer que, en principio, no lo desea.

\subsubsection{Erotización del sufrimiento de las mujeres}

En este apartado presentaremos vídeos que erotizan situaciones de violencia sexual en que ellas muestran claramente que están sufriendo.

En el vídeo Obligada a satisfacer a sus secuestradores, dos hombres introducen por la fuerza en una furgoneta a una mujer mientras en el vídeo aparecen las palabras Road rape («Violación en la carretera»). La llevan a una granja, le atan las manos mientras ella intenta soltarse, le rajan la ropa con una navaja hasta desnudarla mientras ella se retuerce y la violan durante casi 48 minutos en los que ella no para de gritar, llorar e intentar liberarse. El vídeo tenía 8.059.655 visitas a día 14/02/2018 y un $100 \%$ de votos positivos.

Hemos encontrado más vídeos en que vemos cómo ellas gritan de manera desgarradora, lloran angustiadas, se retuercen, tratan de liberarse; y cómo ellos responden pegándolas, agarrándolas del cuello, tirándoles del pelo, metiéndoles el pene en la boca, inmovilizándolas, atándolas, escupiéndolas u orinando sobre ellas.

Cuando un varón se masturba con estos vídeos, se está excitando directamente con el dolor, la angustia y el sufrimiento de esas mujeres. Así, no solo le parecerá excitante la idea de confirmar su masculinidad y su poder, sino que habrá aprendido que también es excitante si eso produce dolor y sufrimiento a la mujer que tenga en frente; situación que puede encontrar en la prostitución. La erotización de la violencia sexual alcanza en estos vídeos su máxima expresión.

\subsubsection{Erotización de la humillación de las mujeres}

En algunos casos, la pornografía se revela como un catálogo de prácticas humillantes para las mujeres. Encontramos vídeos en que los varones orinan y defecan sobre o dentro de las mujeres (utilizan a veces unos aparatos metálicos que les mantienen algunos de sus orificios abiertos, ya sea la boca, la vagina o el ano, para hacerlo más fácilmente), las penetran mientras meten su cabeza en retretes, eyaculan en sus ojos, las ponen en posiciones que no parecen tener más función que pro- 
ducirles dolor, les pisan la cabeza contra el suelo mientras las penetran, les llenan la boca de semen y les tapan la nariz hasta que se atragantan, etc.

En muchos casos, como afirma Núñez (2016), parece que la pornografía se hace «una sola pregunta, obsesiva, definitiva: ¿qué más se le puede hacer a una tía? $\mathrm{O}$, lo que es lo mismo: ¿Cómo se puede degradar y humillar más a una puta?» Efectivamente, «la pornografía actual constituye un extenso, misógino y pedagógico registro de violencia contra las mujeres en sus más diversas y crueles formas. Es, por tanto, un cauce hacia la violencia sexual y la prostitución» (Sambade, 2017: 178). La pornografía, entre otras cosas, ofrece un amplio catálogo de prácticas humillantes y degradantes para las mujeres; prácticas que, en muchos casos, los varones sólo van a poder llevar a cabo acudiendo a un prostíbulo.

\subsubsection{Erotización de los abusos sexuales a menores}

La pornografía hegemónica ofrece también un amplio catálogo de vídeos en que se erotizan los abusos sexuales a menores. No nos referimos solo a la infantilización de las mujeres, sino a vídeos en que realmente aparecen niñas. Una categoría concreta, Barely legal (Apenas legal) muestra chicas con caras de niñas y apenas desarrolladas. Los vídeos en que el título anuncia que la chica que aparece es virgen y sangra durante la penetración también son abundantes.

En el vídeo Primera vez de una adolescente, con 22.029 .843 visitas a 12/02/2018, encontramos una chica claramente menor de edad a la que un varón penetra vaginalmente. Ella no hace ningún tipo de sonido y su cara se mantiene inexpresiva. En el vídeo Perra culona tiene brutal sexo anal / anal doloroso con lamida en un carrito de compras, vemos en un almacén a una chica también menor de edad a la que han colgado un cartel en que pone « 5 dólares». Dos hombres vestidos, uno de ellos enmascarado, le introducen el pene en la boca mientras le tiran del pelo y le pegan en la cara. La inmovilizan atándola para penetrarle anal y bucalmente. Durante diez minutos la escuchamos llorar y hacer ruidos de dolor y vemos primeros planos de su cara, empapada. El vídeo tiene 6.245.942 visitas.

Según un estudio de Online MBA, al día hay 116.000 búsquedas de vídeos de pornografía con menores (Mendiola, 2010). Estos vídeos alimentan el deseo sexual masculino de abusar de niñas. Esto, por un lado, podemos relacionarlo con los abusos sexuales en la infancia: en España, el 15,2\% de los varones y el 22,5\% de las mujeres han sufrido abusos sexuales en su infancia; el $90 \%$ de los abusadores son varones, y el 85\% de los casos se dan dentro de la familia (Luna, 2010). Por otro lado, podemos relacionarlo con la trata de menores con fines de explotación sexual. Humanium calcula que, cada día, 4.000 niños/as son víctimas de trata $(1.460 .000$ cada año).

\subsubsection{Erotización del consumo de prostitución}

Los vídeos en que se erotiza el consumo de prostitución también están muy presentes en las páginas de pornografía hegemónica. Algunos títulos son Úsalas hasta 
romperlas - cómo tratar putas de la manera correcta (2.721.772 visitas a 17/03/2918), Polla gigantesca desgarrando puta flaquita (16.956.361 visitas a 17/03/2018), Hermana puta golpeada por hermano (14.905.801 visitas a 17/03/2018), Colegiala puta es follada por tres pollas negras (13.689.782 visitas a 17/03/2018), Mi hermanastra es una putilla caliente (13.157.067 visitas a 17/03/2018), Puta zorra solo quiere follar (11.540.788 visitas a 17/03/2018) ... En estos vídeos los niveles de humillación son más intensos. Podemos observar cómo, aunque la pornografía tiende a transmitir el mensaje de que «todas son unas putas», cuando se explicita que lo son parece que hay mayor legitimidad para que el varón haga cualquier cosa.

\section{Conclusiones: ¿Por qué tantos varones consumen prostitución?}

Es la demanda masculina de prostitución lo que hace que esta se mantenga, lo que hace que se sigan mercantilizando cuerpos de mujeres y niñas. Por ello, en este artículo nos hemos propuesto analizar cómo se construye el deseo sexual masculino prostituyente.

Como hemos mencionado, el único elemento que comparten los puteros es haber sido socializados en el género masculino. Dentro de esta socialización, «las características que definen este perfil (el del putero) son la carencia de empatía hacia las mujeres y la vivencia de la sexualidad como una forma de confirmación de la masculinidad basada en su dominación» (Sambade, 2017: 175).

Para que los varones puedan mantener relaciones sexuales con alguien que no lo desea, deben pasar varias cosas. Por un lado, debe haber un distanciamiento emocional que se aprende en la socialización masculina y que se refuerza con la cosificación y la sexualización de las mujeres. Sólo considerando que la mujer que tienen delante es un objeto sexual y no una persona cuyas emociones y deseos son relevantes se puede pasar por encima de su falta de deseo o de su dolor. Por otro lado, debe haber una connotación erótica de la falta de deseo, del dolor físico e incluso del sufrimiento emocional de las mujeres. Esto es lo que les ofrece la pornografía hegemónica, que reproduce un modelo de sexualidad que reduce a la mujer a objeto sexual y pone el deseo del varón en el centro, como único factor relevante. La prostitución responde claramente a este esquema. Además, se ha convertido en uno de los espacios donde se pueden llevar a cabo algunas de las prácticas que la pornografía muestra como placenteras para ellos.

La masculinidad hegemónica requiere de una confirmación constante de la capacidad de dominar a las mujeres; dominación que parte de una devaluación de estas que permite a los varones afirmarse como superiores. La sexualidad se ha convertido en uno de los terrenos en que los varones siguen tratando de confirmar dicha capacidad. Esta masculinidad hegemónica, que se está viendo tan perseguida en otros terrenos, encuentra en el prostíbulo un lugar ideal para refugiarse y reforzarse (Gimeno, 2012: 77). Hablamos de un deseo que es a la vez un deseo sexual y un deseo de confirmar la masculinidad. Así, la prostitución es funcional para el mantenimiento del orden patriarcal dado que perpetúa y fortalece roles y estereotipos de género. 
El prostíbulo es además un espacio al que acudir en manada, un espacio en que pueden mostrar a los demás varones que son uno más del grupo de iguales, alimentando la fratría. La prostitución permite al varón, en palabras de Gómez (2017: 154) «"ser un macho" o, por lo menos, parecerlo a los ojos del grupo de pares».

Ir de putas se convierte en una estrategia más para dejar bien claro que se es un hombre de verdad. Lo cual implica, desde la concepción hegemónica que estamos analizando, la capacidad de dominar al 'otro', o sea, a la mujer. Un dominio que es el que vemos sexualizado y erotizado de manera permanente en la pornografía (Salazar, 2017: 165).

Así, no sería exacto decir que los varones que consumen prostitución están pagando únicamente por mantener relaciones sexuales. Los puteros «no sólo encuentran placer en la satisfacción de sus deseos, sino también y fundamentalmente en la confirmación de la masculinidad hegemónica a través de una experiencia de poder sin reciprocidad» (Sambade, 2017: 176). Parece más exacto decir que están pagando por poder poner en práctica un tipo de sexualidad que les permite sentirse superiores a las mujeres por medio de la deshumanización de estas. Consideramos que esta sexualidad masculina no tiene cabida en una sociedad verdaderamente igualitaria.

En este artículo se ha tratado de mostrar cómo la mercantilización de los cuerpos de las mujeres en la prostitución responde a una demanda generada por una construcción concreta de la masculinidad. Lo que creemos que, como sociedad, debemos preguntarnos, es: ¿qué podemos hacer con esta masculinidad que perpetúa una de las situaciones más trágicas e injustas del mundo actual, a saber, la mercantilización y la explotación sexual de tantas mujeres y niñas?

\section{REFERENCIAS BIBLIOGRÁFICAS}

Amorós Puente, Celia (2006). La gran diferencia y sus pequeñas consecuencias... para las luchas de las mujeres, Madrid: Ediciones Cátedra.

APRAMP (2011). «La trata con fines de explotación sexual», en APRAMP. Disponible en: https://apramp.org/download/la-trata-con-fines-de-explotacion-sexual/ (Fecha de consulta: 11/01/18).

Askabide (2008). Perfil de clientes de prostitución en Bizkaia, Bilbao: Mensajero.

Ayuntamiento de Sevilla (2011). Ordenanza municipal contra la explotación sexual, Sevilla: Ayuntamiento de Sevilla.

Barahona Gomariz, María José y Luis Mariano García Vicente (2003). Una aproximación al perfil del cliente de prostitución femenina en la Comunidad de Madrid, Madrid: Dirección General de la Mujer.

Beasley, Christine (2008). «Rethinking Hegemonic Masculinity in a Globalizing World» en Men and Masculinities, N¹1-1, pp. 86-103.

Сово Bedía, Rosa (2017). La prostitución en el corazón del capitalismo, Madrid: Catarata. 
Comisión para la Investigación de Malos Tratos a Mujeres (2006). «El cliente de prostitución: de invisible a responsable». Disponible en: http:/ / malostratos. org/wp-content/uploads/2017/09/Cliente-web.pdf (Fecha de consulta: 11/01/18).

Connell, Raewyn (1995). Masculinities, Berkeley: University of California Press.

De Beauvoir, Simone (1949). El segundo sexo, Buenos Aires: Siglo XX.

De Miguel Álvarez, Ana (2012). «La prostitución de mujeres, una escuela de desigualdad humana» en Revista europea de derechos fundamentales, No19, pp. 49-74.

De Miguel Álvarez, Ana (2015). Neoliberalismo sexual. El mito de la libre elección, Madrid: Ediciones Cátedra.

EKIS EKMAN, Kajsa (2017). El ser y la mercancía: prostitución, vientres de alquiler y disociación, Barcelona: Bellaterra.

EscalADA, Leire (2016). "Amelia Tiganus, superviviente de prostitución y trata: "Acostarse con 15 hombres en una noche no es un trabajo"», en Navarra.com. Disponible en: https://navarra.elespanol.com/articulo/sociedad/ameliatiganus-superviviente-prostitucion-y-trata/20160621165050050767.html (Fecha de consulta: $19 / 03 / 18)$.

FAvaro, Laura (2015). "Porn Trouble" On the Sexual Regime and Travels of Postfeminist Biologism» en Australian Feminist Studies, Vol. 86, No30, pp- 366-376.

Favaro, Laura y Ana De Miguel Álvarez (2016). «¿Pornografía feminista, pornografía antirracista y pornografía antiglobalización? Para una crítica del proceso de pornificación cultural» en Labrys, No29.

Feminario de AlicAnte (1987). Elementos para una educación no sexista: Guía didáctica de la coeducación, València: Víctor Orenga.

GilmoRe, David (1994). Hacerse hombre: concepciones culturales de la masculinidad, Barcelona: Paidós.

Gimeno, Beatriz (2012). La prostitución, Barcelona: Edicions Bellaterra.

Gómez SuÁrez, Águeda (2017). «Masculinidad y gramática sexual del "putero"» en Nuño Gómez, Laura y Ana De Miguel Álvarez (dirs.) y Lidia Fernández Montes (coord.) (2017). Elementos para una teoría crítica del sistema prostitucional, Granada: Editorial Comares, pp. 142-156.

Gómez SuÁrez, Águeda; Pérez Freire, Silvia y Rosa María Verdugo Matés (2015). El putero español: quiénes son y qué buscan los clientes de prostitución, Madrid: La Catarata.

Herranz Gómez, Yolanda (2006). Igualdad bajo sospecha. El poder transformador de la educación, Madrid: Narcea.

Humanium (2018). «Trata infantil». Disponible en: https://www.humanium.org/ es/trata-ninos / (Fecha de consulta: 09/02/18).

López FAUSTE, Ismael (2017). Escúpelo: crónicas en negro sobre el porno en España, A Coruña: Tandaia.

López Insausti, Rafael y David Baringo (2006). Nadie va de putas: el hombre y la prostitución femenina, Zaragoza: Logi Organización Editorial.

LunA, Victoria (2010). "Abusos sexuales a menores: cuando el monstruo vive en casa», en 20 minutos. Disponible en: https://www.20minutos.es/ noticia/881449/0/abusos/sexuales/infancia/ (Fecha de consulta: 19/03/18). 
MARquÉs, Josep-Vicent y Raquel Osborne (1991). Sexualidad y sexismo, Madrid: UNED. Mendiola, José (2010). «Locos por el porno», en El Confidencial. Disponible en: https://www.elconfidencial.com/tecnologia/2010-06-10/locos-por-elporno_890563/ (Fecha de consulta: 09/02/18).

Meneses Falcón, Carmen (2010). «Factores motivacionales en una muestra de hombres españoles que pagan por servicios sexuales» en Revista Asociación Española Neuropsiquiatría, Vol. 107, N330, pp. 393-407.

Meneses Falcón, Carmen (coord.) (2016). Apoyando a las víctimas de trata. Las necesidades de las mujeres víctimas de trata con fines de explotación sexual desde la perspectiva de las entidades especializadas y profesionales involucradas. Propuestas para la sensibilización contra la trata, Madrid: Ministerio de Sanidad, Servicios sociales e Igualdad. Disponible en: http://ibdigital.uib.es/greenstone/collect/portal_ social/index/assoc/msan0182.dir/msan0182.pdf (Fecha de consulta: 11/01/18).

Meneses Falcón, Carmen y Antonio Rua Vieites (2011). «Comportamientos de riesgo en los varones que pagan servicios sexuales» en Norte de Salud Mental, Vol. 39, No9, pp. 27-39.

NúÑEZ, Gabriel (2016). «El porno feroz. La misoginia como espectáculo», en El estado mental. Disponible en: https://elestadomental.com/diario/el-pornoferoz (Fecha de consulta: 15/01/18).

NuÑo Gómez, Laura (2016). «Una nueva cláusula del Contrato Sexual: vientres de alquiler» en Isegoría, No55, pp. 683-700.

Nuño Gómez, Laura y Ana De Miguel Álvarez (dirs.) y Lidia Fernández Montes (coord.) (2017). Elementos para una teoría crítica del sistema prostitucional, Granada: Editorial Comares.

ONu (2010). The globalization of crime. A transnational organized crime threat assessment, Nueva York: Naciones Unidas.

Puleo, Alicia (1992). Dialéctica de la sexualidad. Género y sexo en la filosofía contemporánea, Madrid: Cátedra.

RANEA Triviño, Beatriz (2016). «Analizando la demanda: relación entre masculinidad hegemónica y prostitución femenina» en Investigaciones feministas: papeles de estudios de mujeres, feministas y de género, Vol. 2, No7, pp. 313-330.

RANEA TRIVIÑo, Beatriz (2017). "(Re)pensar la prostitución desde el análisis crítico de la masculinidad» en Nuño Gómez, Laura y Ana De Miguel Álvarez (dirs.) y Lidia Fernández Montes (coord.) (2017). Elementos para una teoría crítica del sistema prostitucional, Granada: Editorial Comares, pp. 135-142.

SAlazar Benítez, Octavio (2017). «Prostitución y desigualdad: la necesaria deslegitimación de los sujetos prostituyentes» en NuÑo GómEz, Laura y Ana DE Miguel Álvarez (dirs.) y Lidia Fernández Montes (coord.) (2017). Elementos para una teoría crítica del sistema prostitucional, Granada: Editorial Comares, pp. 157-168.

SAMBAdE BAquerín, Iván (2017). «La instrumentalización de la sexualidad. Masculinidad patriarcal, pornografía y prostitución» en NuÑo GómEZ, Laura y Ana De Miguel Álvarez (dirs.) y Lidia Fernández Montes (coord.) (2017). Elementos para una teoría crítica del sistema prostitucional, Granada: Editorial Comares, pp. 169-180. 
Simón, María Elena (2010). La igualdad también se aprende. Cuestión de coeducación, Madrid: Narcea S. A.

Subirats Martori, Marina y Cristina Brullet Tenas (1988). Rosa y azul. La transmisión de los géneros en la escuela mixta, Madrid: Instituto de la Mujer.

Subirats Martori, Marina (1999). «Género y escuela» en Lomas, Carlos (comp.)

(1999). ¿Iguales o diferentes? Género, diferencia sexual, lenguaje y educación, Barcelona: Paidós, pp. 19-32.

Subirats Martori, Marina y Amparo Tomé González (1992). «Pautas de observación para el análisis del sexismo en el ámbito educativo» en Cuadernos para la coeducación, No2, Barcelona: Institut de Ciències de l'Educació/UAB.

SUBIRATS MARTORI, Marina (2013). Forjar un hombre, moldear una mujer, Barcelona: Aresta. SzIL, Peter (2006). «Los hombres, la pornografía y la prostitución». Disponible en: http://szil.info/es/system/files/document/101-hombres-pornografiaprostitucion.pdf (Fecha de consulta: 02/02/18).

WALKER, Natasha (2010). Muñecas vivientes: el regreso del sexismo, Madrid: Turner.

\section{RECURSOS ELECTRÓNICOS}

«Adolescente se despierta con el pene de su hermanastro en la boca, se lo folla mientras sus padres duermen", en Pornhub. Disponible en: es.pornhub.com/ view_video.php?viewkey=ph55e1ffadf40a0 (Fecha de consulta: 19/03/18).

«Colegiala puta es follada por tres pollas negras», en Pornhub. Disponible en: https:/ /es.pornhub.com/view_video.php?viewkey=3c1fddcc0e61614d6671 (Fecha de consulta: 19/03/18).

«Hermana puta golpeada por hermano», en Pornhub. Disponible en: https:// es.pornhub.com/view_video.php?viewkey=ph59417d9785bb6 (Fecha de consulta: 19/03/18).

«Hermanastro se aprovecha de su hermana pequeña», en Pornhub. Disponible en: es.pornhub.com/view_video.php?viewkey=1550066665 (Fecha de consulta: 19/03/18).

«Mi hermanastra es una putilla caliente», en Pornhub. Disponible en: https:// es.pornhub.com/view_video.php?viewkey=ph57453c4917516 (Fecha de consulta: 19/03/18).

«Obligada a satisfacer a sus secuestradores», en Xvideos. Disponible en: http:// www.xvideos.com/video2624302/forced_to_please_her_kidnappers (Fecha de consulta: 19/03/18).

«Padrastro se coge a la hija y a sus amigas», en Pornhub. Disponible en: es.pornhub. com/view_video.php?viewkey=999592147 (Fecha de consulta: 19/03/18).

«Perra culona tiene brutal sexo anal / anal doloroso con lamida en un carrito de compras», en Pornhub. Disponible en: https://es.pornhub.com/view_video. php?viewkey=568400137 (Fecha de consulta: 19/03/18).

«Polla gigantesca desgarrando puta flaquita», en Pornhub. Disponible en: https:// es.pornhub.com/view_video.php?viewkey=333472364 (Fecha de consulta: 19/03/18). 
«Pornhub categorías», en Pornhub. Disponible en: https://es.pornhub.com/ categories (Fecha de consulta: 19/03/18).

«Pornhub gay», en Pornhub. Disponible en: https://es.pornhub.com/gayporn (Fecha de consulta: 19/03/18).

«Pornhub heterosexual», en Pornhub. Disponible en: https://es.pornhub.com/ (Fecha de consulta: 19/03/18).

«Primera vez de una adolescente», en Xvideos. Disponible en: http://www. xvideos.com/video29674415/first_time_teen_more_at_superhornygirlscam. com (Fecha de consulta: 19/03/18).

«Puta zorra solo quiere follar», en Pornhub. Disponible en: https://es.pornhub. com/view_video.php?viewkey=2073425039 (Fecha de consulta: 19/03/18).

«Ranking de Alexa», en Alexa.com. Disponible en: https://www.alexa.com/ topsites/countries/ES (Fecha de consulta: 19/03/18).

«Ranking de Webempresa», en Webempresa. Disponible en: https://www. webempresa20.com/blog/webs-mas-visitadas-en-espana.html (Fecha de consulta: 19/03/18).

«Salvados: las invisibles», en Atresplayer. Disponible en: http:/ /www.atresplayer. com/television/programas / salvados / temporada-13 / capitulo-14-lasinvisibles_2018030900957.html (Fecha de consulta: 19/03/18).

«Taxi falso estudiante inocente hace sexo anal en el asiento de atrás», en Youporn.

Disponible en: www.youporn.com/watch/9320353/faketaxi-innocent-studentdoes-backseat-anal/ (Fecha de consulta: 19/03/18).

«Úsalas hasta romperlas - cómo tratar putas de la manera correcta», en Pornhub. Disponible en: https://es.pornhub.com/view_video. php?viewkey=ph57dd5d75a715f (Fecha de consulta: 19/03/18).

«Xvideos», en Xvideos. Disponible en: www.xvideos.com (Fecha de consulta: 19/03/18).

Recibido el 30 de marzo de 2018

Aceptado el 24 de julio de 2018 BIBLID [1132-8231 (2018): 61-79] 